\title{
El lactario del Hospital Manuel Arriarán. Dos años de funcionamiento
}

\author{
Publicado en Revista Chilena de Pediatría 1938
}

Autor: Arturo Baeza Goñi

Comentario al artículo: Luisa Schonhaut B. y Patricia Salinas A.

Palabras clave: Lactario, Banco Leche Humana, Lactancia Materna, Historia pediatría.

Key words: Human Milk Bank, Brest feeding, Pediatric History.

\section{Introducción y marco histórico}

Conociendo los enormes beneficios de la lactancia materna para la nutrición de los niños, a principios del siglo XX ya se realizaban importantes actividades para su fomento". " $L a$ alimentación natural, a pesar de los grandes progresos realizados en la técnica de la alimentación artificial sigue $y$, sin duda, seguirá siendo el alimento ideal para el lactante sano, y para el lactante enfermo constituye también el alimento curativo por excelencia." (Baeza Goñi A. 1937)².

No obstante, hace 75 años, el país enfrentaba una "franca crisis" en el "abastecimiento de cantidades suficientes de leche de mujer", tanto para la alimentación diaria de los niños que crecían el en seno de sus familias, como para aquellos internados en hospitales o en hogares de menores " $y$ de ahi que al tener que recurrir a él se plantea un problema, a veces de angustiosa solución". (Baeza Goñi A, 1937)².

Se atribuía la crisis de la alimentación con leche materna a "la civilización moderna que a la mujer va atrofiando el sentido maternal" el que secundariamente provocaba la "atrofia progresiva del poder secretor del seno materno". El "modernismo, que rige aún para las líneas de la silueta femenina, la cual víctima de ello se somete a fantásticos regímenes para adelgazar" era considerado la principal amenaza en las clases acomodadas, mientras que en los sectores más populares, lo era la "miseria y la subnutrición".

En el caso de los niños institucionalizados, cuya mortalidad era elevadísima e iba paralela con una alta morbilidad de los que aún estaban vivos $^{3}$. Era necesario encontrar alguna solución con urgencia. Ariztía y Eggers, realizaron distintos ensayos, "yendo desde la alimentación predominante con leche humana mercenaria, mediante amas que vivian dentro del establecimiento con sus propios hijos, hasta los regímenes artificiales más variados, complicados y poco conocidos, siempre en busca de la fórmula ideal que permitiera resolver el problema del progreso pondoestatural y psíquico normal del lactante, unida a una inmunidad suficiente". Las amas, además de proveer leche materna, "ayudaban en la atención de los asilados y sus hijos convivían con aquellos, corriendo igual suerte frente a la amenaza del hospitalismo y de las epidemias"4. 
Buscando resolver esta crisis de la alimentación infantil, $\mathrm{y}$, al mismo tiempo evitar caer en la "Lactancia Mercenaria, verdadera plaga que ha azotado durante tantos años a los niños de todas partes del mundo" ..." y que culminan generalmente con la muerte de los hijos de estas amas", los pediatras reaccionaron con dos grandes estrategias: el fomento de la lactancia materna y el desarrollo de la alimentación artificial, pese al temor que pudiese competir contra la lactancia natural, al ser presurosamente introducidas por un "pediatra poco experimentado" (Baeza Goñi A. 1938).

En relación al Fomento de la lactancia materna, Baeza Goñi proponía: a) generar un consenso Panamericano relacionado la obligación que tienen las madres amamantar a sus hijos; b) comprometer al Gobierno a fomentar la crianza materna a través de leyes de protección social; c) Organización de "Centros recolectores y distribuidores de leche de mujer" o Bancos de Leche, con el objeto de reunir "el excedente de leche que poseen un número considerable de madres, para distribuirlo entre aquellos niños que la necesitan y no pueden procurársela de otra manera".

El presente artículo relata la experiencia de 2 años de funcionamiento del lactario del Hospital Manuel Arriarán, que comenzó "modestísimamente en noviembre del año 1935 con un capital de \$200"2.

\section{Artículo Baeza Goñi}

Mucho ha progresado la dietética infantil, en lo que se refiere a la alimentación del lactante sano o enfermo, en los últimos años e innumerables preparados han sido señalados como sustitutos de la leche de mujer. Sin embargo, sin dejar de reconocer el progreso inmenso realizado con alimentos tales como la leche albuminosa, el Babeurre, los regímenes sin leche, etc., el pediatra, a medida que su experiencia aumenta, cuando quiere rodearse de un maximum de garantías sobre la salud y la vida de los niños a su cargo, ya sea en los servicios clínicos o en la clientela particular, primero que en cualquier otro alimento, piensa en la leche de mujer; por cuanto este alimento es y seguirá siendo el alimento ideal del lactante.
No podemos negar, por cierto, que también la experiencia nos enseña que en ciertos casos de toxicosis, en que el metabolismo celular está profundamente dañado, en que el elemento deshidratación parece ya irreversible, no se obtiene con la leche de mujer el éxito constante que se observa en la generalidad de los trastornos nutritivos del lactante, pero, sin duda que estos casos no abundan por su frecuencia, felizmente. No creemos, por lo tanto, útil insistir sobre ello.

Las verdaderas dificultades se encuentran indiscutiblemente en el abastecimiento de cantidades suficientes de leche de mujer, tanto para los servicios clínicos como para los niños que a domicilio carecen hoy día más que nunca de este precioso alimento.

En realidad, la alimentación materna se encuentra en una franca crisis. Nos preguntamos, es la civilización moderna que a la mujer va atrofiando el sentido maternal y, por ende, su naturaleza responde con una atrofia progresiva del poder secretor del seno materno? En las clases ricas es, indiscutiblemente, el modernismo, que rige aún para las líneas de la silueta femenina, la cual víctima de ello se somete a fantásticos regímenes para adelgazar, el que fatalmente determina esta hipogalactia progresiva que vemos a diario los pediatras. En el polo opuesto, encontraremos a la mujer de las clases pobres, en las cuales la miseria y la subnutrición agotan precozmente la secreción láctea; el industrialismo, por otra parte, completa esta desmedrada situación en que se encuentran los hijos de millares y millares de madres en la época actual.

Sería también de considerar si no tiene influencia activa en este orden de cosas el mismo perfeccionamiento de la alimentación artificial que hace que muchas madres en gran parte, pierdan el temor saludable que existía antes a este propósito y que muy prematuramente proceden al destete de sus hijos, no rara vez sugestionando al pediatra poco experimentado que se deja fácilmente engañar por una hipogalactia remediable o pasajera.

Sería, creemos, digno de interés que en esta reunión panamericana, una vez más señaláramos los grandes peligros de este estado de cosas y que de ella saliera una autorizada re- 
comendación, mejor dicho una categórica indicación sobre la necesidad de insistir ante las madres de América, en la obligación que ellas tienen de amamantar a sus hijos, para fortalecer así la raza y paralela a ella otra indicación a los Gobiernos para que por todos los medios a su alcance, estimulen la crianza materna y protejan eficazmente a la madre para que críen a sus hijos.

Estas consideraciones y otras análogas que se refieren a la lactancia mercenaria, verdadera plaga que ha azotado durante tantos años a los niños de todas partes del mundo, han influido en el ánimo de aquellos que se han preocupado de solucionar el magno problema que significa procurarse las cantidades de leche de mujer necesarias al lactante sano o enfermo que carece del seno materno. Fruto de ellas ha sido la organización de Centres recolectores y distribuidores de leche de mujer.

El problema a primera vista parecía senci1lo, pero en realidad es susceptible de ser considerado desde diversos puntos de vista, algunos de ellos especialmente delicados. Desde luego existe el peligro de la comercialización de la leche de mujer, en desmedro efectivo de los derechos del propio hijo, en seguida existe el peligro mismo que una leche de mala calidad obtenida en cualquier forma puede constituir, existe, además, el peligro del fraude.

Todos estos aspectos bien considerados, exigían una organización bien concebida y que como condición sine quanon requiere el control médico social más estricto.

Cabe a nuestro estimado colega, el médico argentino Dr. Saúl Bettinotti, el merecido honor de haber dado forma cabal y precisa a esta clase de organismos, al establecer los principios sobre los cuales debe descansar la organización de los Lactarios. Esto, sin dejar de reconocer que nuestro ilustre colega uruguayo, el Dr. Bauza, fuera tal vez el primero en América que se preocupara de esta interesante cuestión.

Bettinotti ha definido el Lactario como "una institución del Estado que sin fines de lucro, tiene un propósito médico social, que consiste en extraer, conservar y distribuir leche de mujer y, además, evitar los inconvenientes de la lactancia mercenaria".

En esta definición está comprendido en toda su amplitud el substratum médico y social, sobre el cual debe descansar un Centro de Recolección de leche de mujer o como con tanto acierto lo llama el colega Bettinotti, un Lactarium, y al ser ella aplicada con propiedad, se obtiene de esta clase de organismos los grandes beneficios que están destinados a producir y se evitan los evidentes perjuicios que necesariamente acarrearía un funcionamiento sin el debido control médico social, ya que es necesario partir de la base de que la leche que en los Lactarios se va a recibir, debe ser aquel exceso que muchas madres tienen después de alimentar a sus hijos y que, por lo tanto, el control fundamental debe ser ejercido sobre estos para que en ningún caso suceda el hecho desgraciado de que una madre, por simple afán de lucro, perjudique directamente a su hijo, robándole el derecho inalienable que éste posee sobre el seno materno.

Concebido de idéntica manera, hemos organizado en el Hospital de Niños Manuel Arriarán, hace ya más de dos años, un Lactario destinado, en primer lugar, a proporcionar leche de mujer a los lactantes hospitalizados en nuestro Servicio de Lactantes y por otra parte, al expendio de ella a la clientela particular de los médicos a domicilio.

El procedimiento es el siguiente, se recibe a toda dadora que se ofrece a vender su leche, previo un examen clínico, radiológico y serológico completo y después de un control minucioso del desarrollo de su hijo. Se les inscribe a ambos en una ficha especial y mediante exámenes periódicos se les vigila, estando alerta sobre cualquier signo que nos pueda indicar una alteración de la madre o del niño, lo cual motiva la suspensión temporal o definitiva de la dadora.

La ordeña se hace dos veces al día, en forma manual. En realidad, por falta de recursos no hemos establecido la ordeña mecánica tan recomendada por otros autores, muy especial por Bettinotti, pero debemos establecer que el conocimiento de los peligros que ella encierra, nos ha hecho extremar el control sobre la limpieza, por no decir sobre la verdadera asepsia con que ella se ejecuta y los resultados alcanzados, controlados por exámenes bacteriológicos que se practican diariamente, nos dejan enteramente satisfechos al respecto. 
Nuestro Lactario, después de dos años de funcionamiento, ha demostrado hasta la evidencia las ventajas enormes que esta clase de organismos poseen y la utilidad indiscutible que ellos representan, en primer lugar, para las instituciones cerradas de asistencia del lactante y la necesidad imperiosa que ellos vienen a llenar cuando se trata de la atención de lactantes a domicilio. Creemos firmemente que los Lactarios merecen el franco y decidido apoyo de los organismos médicos en general, así como también muy en particular del Estado y de los municipios. Sólo mediante ellos se podrá contar en el porvenir con las cantidades suficientes de leche de mujer para atender y salvar innumerables vidas de niños y lo que es igualmente de Importancia trascendental, sólo mediante la multiplicación de estos lactarios, se podrá luchar en forma eficaz y decidida contra la lactancia mercenaria, que tantas y tantas vidas infantiles ha tronchado.

No creemos necesario insistir en mayores detalles sobre esta clase de instituciones que, como otra prueba de su gran eficacia, han sido comprendidas con extraordinaria rapidez, tanto en los círculos científicos como sobre todo por el público en general, precisamente porque cada día aumenta más y más el considerable número de niños que han salvado su vida, gracias a que en los Lactarios han podido conseguir la cantidad suficiente de leche de mujer que para ello se necesitaba.

Damos a continuación un conjunto de datos obtenidos en el Lactario del Hospital Manuel Arriarán y que encierran la experiencia obtenida en los dos años de funcionamiento de este organismo y que mejor que ninguna otra consideración demuestran los hechos antes señalados.

Total de leche recibida en los 2 años

4.651,800 g.

Entregada al Servicio de Lactantes

$2.447,360 \mathrm{~g}$.

Vendida a particulares $2.204,440 \mathrm{~g}$.

Velocidad de extracción manual, calculada en 12 nodrizas. Término medio: $918 \mathrm{cc}$ por hora, es decir, 100 cc en 6' y 30 ".

Velocidad de extracción mecánica, según Jaso (Barcelona), $100 \mathrm{cc}$ en 10' 3'.

\section{Comentario al artículo de Baeza Goñi}

Hace 75 años atrás, los pediatras manifestaban su preocupación por la amenaza de la lactancia natural debido a motivos sociales, estéticos o nutricionales, potenciados por la aparición de las fórmulas lácteas. Pese a las estrategias implementadas, evidentemente el impacto no fue logrado. El año 1974, en Chile, se estimaba que $19 \%$ de los lactantes eran alimentados exclusivamente al pecho hasta los seis meses de edad ${ }^{5}$, cifra que, según encuestas nacionales, se mantuvo sin grandes variaciones 2 décadas después ${ }^{6}$. A partir de principios de este siglo, en que se desarrolló una intensa campaña de promoción de la lactancia materna, a través de los medios de comunicación y la capacitación profesional, esta tasa aumentó significativamente, acercándose al 50\% ${ }^{7}$.

La existencia de Bancos de Leche Humana o lactarium "Institución del Estado que, sin fines de lucro, tiene un propósito médico social, el cual consiste en extraer, conservar y distribuir leche de mujer y además evitar los inconvenientes de la lactancia mercenaria"2. data de comienzos del siglo XX. El primer Banco conocido se fundó en Viena el año 1900 y luego en Boston en 1910; en Chile pasarían prácticamente 3 décadas, en que siguiendo las recomendaciones de Bettinotti en Argentina y Bauza en Uruguay, Baeza Goñi y su equipo implementaran el primer lactario.

Para asegurar su orientación "médico social" era fundamental "el control médico estrictísimo y la protección social amplia, tanto de la madre que entrega la leche como del hijo de ella que es, por cierto, su único y exclusivo dueño"; por ello era necesario mantener un control semanal de la salud, crecimiento y desarrollo de los hijos de madres donantes, el hallazgo de cualquier desviación era considerado indicación de "suspender temporal o definitivamente a la madre del Lactario". Por otro lado se debían prevenir los "fraudes que con relativa frecuencia pueden presentarse" 2 .

Los Bancos de Leche Humana se mantuvieron vigentes, pero con distinto nivel de actividad hasta los años 80 , sin embargo, coincidiendo con la aparición del Sida y otras infecciones de transmisión vertical, la mayoría de 
estas instituciones fueron clausuradas.

No obstante, a lo largo de los años ha habido un nuevo impulso para el funcionamiento de los Lactarios, focalizado en las unidades neonatales, en beneficio de los niños nacidos prematuros, con bajo peso o inmunodeprimi$\operatorname{dos}^{8,9}$. Además se han extremado las normas para la seguridad de la ingesta de leche proveniente de donantes ${ }^{10}$.

Desde hace 2 décadas se ha reconocido que los Bancos de Leche Humana son una de las mejores estrategias sanitarias para la disminución de la mortalidad infantil y protección del amamantamiento, por lo que se han implementado en distintas partes del mundo, con resultados destacables ${ }^{11}$. Siguiendo la tendencia internacional, en Chile se está reevaluando su acreditación, medida que sin duda iría en beneficio de los niños más vulnerables ${ }^{12}$.

\section{Referencias}

1.- Rojas Flores J: Historia de la infancia en el Chile republicano, 1810-2010. World color, Chile 2010.

2.- Baeza Goñi A: EL Lactario del Hospital Manuel Arriarán. Rev Chil Pediatr 1937; 277-81.

3.- Schonhaut B: "Profilaxia del abandono": cien años de protección de la infancia en Chile. Rev Chil Pediatr
2010; 81: 304-12.

4.- Ariztía A, Eggers F: Alimentación artificial del lactante sano en establecimientos cerrados. Rev Chil Pediatr 1942; 13 (2-3): 73-93.

5.- Monckeberg F: Prevención de la desnutrición en Chile experiencia vivida por un actor y espectador. Rev Chil Nutr 2003; 30 (suppl. 1): 160-76.

6.- Comisión Nacional de Lactancia Materna: Efectividad del Programa de Lactancia, Resultados Encuestas Nacionales 1993-2002. Chile, 2005.

7.- Niño R, Silva E, Atalah E: Factores asociados a la lactancia materna exclusiva. Rev Chil Pediatr 2012; 83 (2): 161-9.

8.- $61^{a}$ Asamblea Mundial de la Salud, Resoluciones y Decisiones; Organización Mundial de Salud; Ginebra, Mayo 2008

9.- Nichols $W J r$, Walker A, Woodruff $C W$, et al: Human Milk Banking. Pediatrics 1980; 65: 854.

10.- Cofré $C$ : Bancos de Leche Humana en la Actualidad. La Donación de Leche Humana es una Realidad a Nivel Mundial, ¿Qué Sucede en Chile?. Revista del Colegio de Nutricionistas 2011; 7 (3): 6-9.

11.- Cánepa MA: Un modelo de cooperación horizontal: La Red Iberoamericana de Bancos de Leche Humana (BLH). http://www.paho.org/sscoop/wp-content/ plugins/form/files/15145109Un_modelo_de_cooperacion_horizontal_BLH.pdf

12.- Mena P: Un banco de leche para Chile. Rev Chil Pediatr 2014; 85 (5): 529-32. 